\title{
Impact of Teleconsultation on Patients With Type 2 Diabetes in the Brazilian Public Health System: Protocol for a Randomized Controlled Trial (TELEconsulta Diabetes Trial)
}

Daniela Laranja Gomes Rodrigues ${ }^{1 *}$, MD; Gisele Silvestre Belber ${ }^{1 *}$, MSc; Frederica Valle De Queiroz Padilha ${ }^{1}$, ECON, PhD; Ligia Fonseca Spinel², RN; Frederico Rafael Moreira ${ }^{3}$, BSc; Marcos Aurélio Maeyama ${ }^{4}$, DD, PhD; Ana Paula Neves Marques Pinho², MSc; Álvaro Avezum Júnior ${ }^{3}, \mathrm{MD}, \mathrm{PhD}$

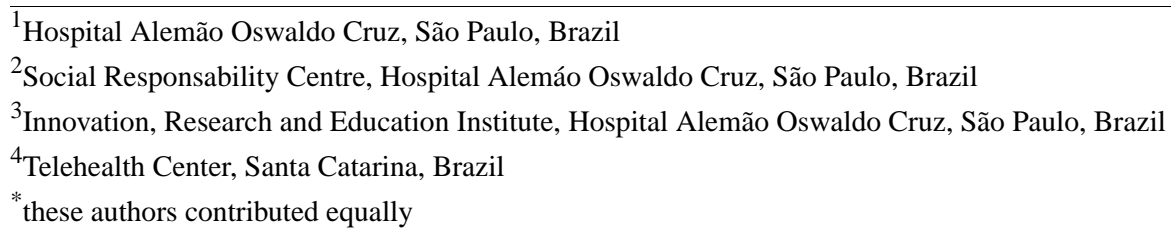

\section{Corresponding Author:}

Daniela Laranja Gomes Rodrigues, MD

Hospital Alemão Oswaldo Cruz

Rua Treze de Maio, 181

São Paulo, 01323-020

Brazil

Phone: 5511985421342

Email: dlgvascular@gmail.com

\section{Abstract}

Background: Although the Brazilian Unified Health System (SUS) offers universal health coverage, access to quality care is often limited by social inequality and location. Although telemedicine has been shown to be an important tool in the efforts to overcome this problem, because it can provide access to specialist care and break the geographical barriers to health care, there are no national studies demonstrating its use in public health.

Objective: This study aims to test the hypothesis that remote consultation can be as effective as standard face-to-face consultation for type 2 diabetes mellitus in the Brazilian public health system and to assess the associated costs related to teleconsultation in public health scenarios, for patients referred from Primary Health Care units of the SUS for specialist care.

Methods: This is a pragmatic, phase 2, unicentric, open-label, noninferiority, blinded allocation, data-blinded, centrally randomized clinical trial. The inclusion criteria will be adults, both sexes, $\geq 18$ years old, glycated hemoglobin $\left(\mathrm{HbA}_{1 \mathrm{c}}\right) \geq 8 \%$. Outcomes will be evaluated by assessing symptoms, laboratory exams, anthropometric measurements, blood pressure, adverse events, and satisfaction level for 6 months. The costs of the teleconsultation will be assessed using the time-driven activity-based costing (TDABC) method to compare the costs with the face-to-face consultations. The noninferiority margin was set at $0.5 \%$. Assuming an SD of 1.3\% for both groups, true difference between the means of zero, and a type I error level of 5\% (one-sided), it was estimated that 117 individuals per group would be necessary to achieve $90 \%$ power. Statistical analysis of the efficacy will be done using intention-to-treat and per-protocol approaches.

Results: The results from this trial will be reported according to the CONSORT guidelines. The trial was approved by the institutional review board on October 5, 2019. Data collection started in January 2019 and is expected to finish in 2022. At the time of manuscript submission, 18 participants were recruited.

Conclusions: Our expectations are that providing remote access to health care will result in improvements in the health and quality of life of patients with type 2 diabetes and reduce costs and that both patients and clinicians will benefit from and be satisfied with this technology.

Trial Registration: Registro Brasileiro de Ensaios Clínicos RBR-8gpgyd; https://ensaiosclinicos.gov.br/rg/RBR-8gpgyd International Registered Report Identifier (IRRID): DERR1-10.2196/23679 
(JMIR Res Protoc 2021;10(1):e23679) doi: 10.2196/23679

\section{KEYWORDS}

remote consultation; diabetes mellitus; telemedicine; telehealth; costs; public health

\section{Introduction}

According to the 2016 Global Burden of Disease [1], despite the increase in both quality of life and access to health care observed since 1990, there are still many countries in which health inequalities remain, particularly in relation to cancer and noncommunicable diseases, such as asthma, chronic obstructive pulmonary disease, and diabetes. These diseases have a significant impact on quality of life [2], and this is particularly true in the case of diabetes, because it has a range of serious complications in situations where it is poorly controlled by the individual, such as cardiovascular disease, chronic kidney disease, blindness, and lower limb amputation [3], many of which could be avoided by providing better access to health care.

Figure 1. Regions of Brazil related to this project.
In 2016, Brazil was ranked 96th among 195 countries regarding access to health care and quality of life, according to the Global Burden of Disease [1]. Despite a slight improvement in the health index (from 46.5 in 1990 to 63.8 in 2016), access to health care is still one of the largest indicators of social inequality [4]. While the inhabitants of São Paulo, Brazil's largest city (Figure 1), have access to 2.81 doctors per 1000 inhabitants, in the northeast region, this proportion is about 1.41 doctors, and in some states, this proportion can even reach $<1$ doctor per 1000 inhabitants [4]. When considering physicians of all medical specialties, almost $70 \%$ of these professionals are concentrated in the south and southeast regions of the country [5]. To improve medical access, there is a need to develop strategies that can not only enhance local primary care but also improve the regulatory processes and the organization of specialized health care in Brazil [6-8].

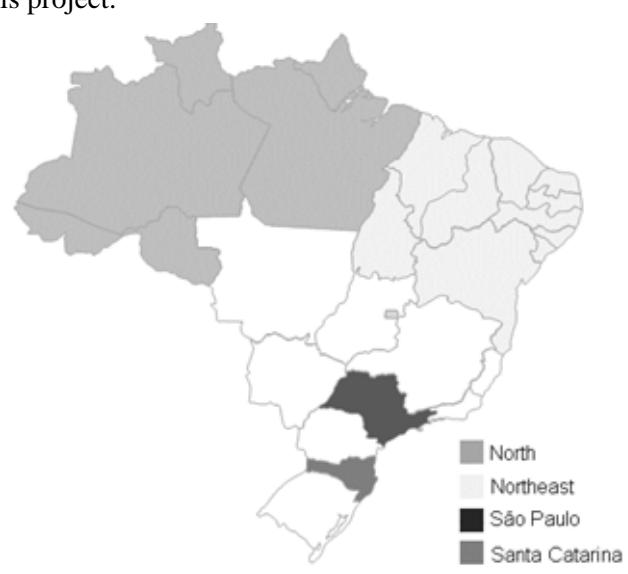

Although there is increasing evidence for the use of remote consultation worldwide [9-11], in Brazil, under Resolution number 1643/2002 [12] of the Federal Council of Medicine, medical consultations by telephone or internet cannot be conducted directly between health professionals and patients. Thus, currently, teleconsulting is only allowed when there is a health professional at both ends of the communication channel, except in the COVID-19 pandemic situation. Also, there are no national studies in Brazil that address the effectiveness and costs involved in teleconsultation service in the public health system. If teleconsulting directly between the physician and the patient can be shown to be safe and effective, this would provide strong evidence to change the current regulations, freeing up one professional from the consultation and driving down costs. The main objective of this study is to test the hypothesis that remote consultation can be as effective as standard face-to-face consultation for type 2 diabetes in the Brazilian public health system and to assess the associated costs related to teleconsultation in public health scenarios.

\section{Methods}

TELEConsult Diabetes is a pragmatic, phase 2, single-center, open-label, noninferiority trial with central randomization that will evaluate the efficacy and safety of specialized remote consultation compared to face-to-face consultation in patients with type 2 diabetes mellitus referred by primary health care units to specialist care in the Unified Health System (SUS) [13].

The inclusion criteria are adults of both sexes, $\geq 18$ years old, established diagnosis of type 2 diabetes, and either not insulin dependent (with any level of glycemic control measured by glycated hemoglobin $\left[\mathrm{HbA}_{1 \mathrm{c}}\right]$ accordingly to local protocol [14-17]) or insulin dependent $\left(\mathrm{HbA}_{1 \mathrm{c}}>8 \%\right)$. Exclusion criteria are patients $<18$ years old or with type 1 diabetes, women with gestational diabetes or diagnosed during pregnancy, and patients with chronic renal failure with estimated or measured creatinine clearance $<30 \mathrm{~mL} / \mathrm{min} / \mathrm{m}^{2}$ [18].

Brazil has a universal public health care system called SUS, which is structured around the principle of primary care and operates by integrating other services and levels of care, such as specialized care, into the system for the whole population. 
The main goal of primary care in Brazil is to provide basic care and to coordinate other levels of care throughout the health system network, regulating referrals to specialist care [8].

The Telehealth Center of Santa Catarina state uses a system that does not represent the reality in most Brazilian states. First, the primary care physicians request a teleconsultation with a specialist. This consultation involves both the primary care physicians and the specialist. Following this first contact, the primary care physician decides whether the patient needs to be referred to a face-to-face consultation with the specialist $[19,20]$. This system of compulsory flow established and operating in Santa Catarina state is the ideal setting to investigate the potential of remote consultation in primary health care, compared to face-to-face consultations.

The participant will be identified by the primary care physician and the Telehealth Center of the state of Santa Catarina, and the regulatory department of the Municipal Health Office of Joinville will determine if she or he meets the eligibility criteria. Patients with type 2 diabetes mellitus may be recruited from any of the city's 70 primary care centers. A researcher will contact the patient by telephone to tell them about the trial and invite them to participate in the study. If the patient agrees, they will be told that they need to provide their written consent, and an informed consent form will be posted to them prior to reading and assessment for their participation in the study. Then, 2-5 days after sending the informed consent form, the researcher will again telephone the patient to confirm their interest in participating in the trial. If the response is still positive, they will schedule a home visit at a convenient time with the patient, in the presence of a legal representative or relative if they so wish. During the visit, any questions related to the study will be answered. After signing and agreeing to participate in this study, the researcher will tell the participant about the next steps: Their data will be randomized in a system created especially for this trial, and they will be scheduled for a face-to-face consultation or for a remote consultation with the specialist. By the end of this home visit, the participant will have been advised about the study, their participation, the date and place of the research consultation, and that there are no costs involved.

To calculate the real cost of a teleconsultation service to compare with the cost of the face-to-face service and to generate a cost parameter for the primary health care units for this type of service, the time-driven activity-based costing (TDABC) method will be used $[21,22]$. In addition to the costs of the resources used, this method also considers the amount of time spent on each stage of the process, enabling the identification of stages where the teleconsultation speeds up or slows down the process, reducing or increasing costs in relation to face-to-face consultation.

This study will also include other indicators, such as the transportation costs for the patients and physicians in a "real-word" scenario, to carry out cost-effectiveness estimates. Finally, we intend to discuss issues related to the reduced costs that increased access to medical care, via teleconsultation, can generate for the system.

The randomization list will be generated electronically using appropriate software. Randomization will be performed in blocks of 4 at a 1:1 ratio. Confidentiality of the randomization list will be ensured by setting up a central database and the use of an electronic case report form. Access to the system will be granted through specific usernames and passwords given to each investigator or study team. The patient will be allocated to one of the treatments (remote consultation or face-to-face consultation) only after being registered in the system. Given the nature of the intervention, blinding is not feasible. However, data analysis will be performed by a statistician blind to patient allocations.

Participants in both groups will be assisted by 1 of a team of 4 endocrinologists from the public outpatient clinic. They will take turns to provide assistance in the 2 modalities. The remote consultation with the intervention group will involve only the specialist and the participant. These consultations will take place in 1 of the 6 primary care units chosen to cover the main regions of the city. In each of these units, the research team set up a room with a computer, microphone, and camera to deliver the remote consultation, assisted by the same team of endocrinologists.

The same physicians will undertake both the remote consultation and the face-to-face consultation, with the same duration (30-60 minutes). All the physicians are specialists medically trained in endocrinology and experienced in caring for patients with diabetes in different settings and as part of the city's specialist care network. A protocol based on national and international guidelines specifically designed for the study [17,23-25] will be used to ensure that all the consultations are as similar as possible. The physicians were instructed to follow the protocol to avoid any bias related to the consultation. The protocol includes instruction on the questions to be asked about the participant's health and the medicines they are using, the scale to be used for hypoglycemia evaluation [26], and the medications to be prescribed (following current guidelines). At the end of the consultation, participants from both groups receive, in addition to medical advice and drug prescriptions, guidance on any laboratory tests that need to be carried out before the next consultation.

The primary outcome will be a change in $\mathrm{HbA}_{1 \mathrm{c}}$ levels at 6 months after randomization. However, we will perform a prespecified analysis 3 months after randomization.

Secondary outcomes will be fasting blood glucose, complete blood count, urea, creatinine, total cholesterol, triglycerides, high-density lipoprotein cholesterol, low-density lipoprotein cholesterol, systolic and diastolic blood pressure, body weight, BMI, frequency of hypoglycemia, and incidence of adverse events. In addition, in the intervention group, we intend to evaluate the satisfaction of the endocrinologists and the patients with the video conference system using a structured questionnaire [23].

A specific quality of life in diabetes questionnaire will be used with patients with diabetes mellitus in the first and last research consultations in both groups [27-29]. In addition, we will estimate the actual cost of the remote consultation service, using the TDABC method [21,22] to obtain the unit cost of remote consultation in the primary health care units. 
This trial is registered with the Ethics and Research Commission (03434218.1.2001.5362).

\section{Results}

This study was approved and funded by the Brazilian Ministry of Health in October 2018 and was approved by the institutional review board in October 2019. Data collection started in January 2019 and is expected to finish in 2022. At the time of manuscript submission, 18 participants were recruited.

The primary objective of this study is to confirm the noninferiority of remote consultation in comparison with face-to-face consultation assessed by the change from baseline in $\mathrm{HbA}_{1 \mathrm{c}}(\%)$ at 6 months. The noninferiority margin was set at $0.5 \%$. Assuming an SD of $1.3 \%$ for both groups, true difference between the means of zero, and a type I error level of 5\% (one-sided), it was estimated that 117 individuals per group would be necessary to achieve $90 \%$ power [30]. In order to accommodate for a maximum dropout rate of $5 \%$, the sample size was increased to 124 individuals per group. Sample size calculation was performed using SAS version 9.4 (SAS Institute Inc, Cary, NC).

The primary endpoint in this study is the change from baseline in $\mathrm{HbA}_{1 \mathrm{c}}(\%)$ at 6 months. The assessment of noninferiority of remote consultation in relation to face-to-face will be conducted according to the CONSORT guidelines [31], using the confidence interval approach to the difference in the mean of the primary variable between the 2 groups. If the upper limit of the $90 \%$ bilateral CI is lower than the established noninferiority margin $(0.5 \%)$, the noninferiority of the remote consultation group relative to the face-to-face group is declared at the $5 \%$ significance level. In addition, an analysis of covariance (ANCOVA) model will be constructed using the main effects of treatment and baseline $\mathrm{HbA}_{1 \mathrm{c}}$ as the covariate.

Adjusted means by treatment will be presented as well as an estimate of the difference between adjusted means. A $90 \%$ 2-sided CI, based on the ANCOVA model, will be computed for the difference between adjusted means. If the upper limit of the $90 \%$ bilateral CI is lower than the established noninferiority margin $(0.5 \%)$, the noninferiority of the remote consultation group relative to the face-to-face group is declared at the $5 \%$ significance level [32-34]. The primary endpoint will be analyzed for the intention-to-treat (ITT) and per-protocol populations. If the proportion of missing data is greater than $5 \%$, sensitivity analyses for missing data imputation will be performed $[35,36]$.

The secondary endpoint is the change from baseline in $\mathrm{HbA}_{1 \mathrm{c}}$ at 3 months, which will be evaluated with ANCOVA. Adjusted means (with $95 \%$ CI) by treatment will be presented. Mixed effects, repeated measures models will be considered for secondary endpoints defined by continuous variables over time (baseline, 3 months, 6 months). Comparison of secondary endpoints defined by categorical data will be evaluated using chi-square or Fisher exact tests. Secondary endpoints will be performed as 2-sided tests with an alpha of 5\%, and 95\% CIs will be reported. The proportion of adverse events will be compared between the 2 groups via a Fisher exact test. The secondary endpoints will be analyzed on the ITT population.

Baseline characteristics will be compared and summarized by treatment groups for the ITT population. Categorical data will be summarized by numbers and percentages. Continuous data will be summarized by mean, SD, and range if data are normal and median and IQR if data are skewed. Normality will be assessed by visual inspection of histograms and with the Shapiro-Wilk normality test [36]. Baseline variables will be compared with the chi-square test or Fisher exact test for categorical variables and the $t$ test or Mann-Whitney test for continuous variables. Statistical analyses will be performed using SAS version 9.4.

\section{Discussion}

Brazil is a country of continental proportions, with great heterogeneities and gaps in access to health care, types of health services, and specialized medical professionals. Lack of access to health services is one of the main indicators of social inequality in Brazil. Thus, to improve access, there is a need to build strategies that impact primary health care, the processes that regulate access, and the organization of specialist care. In this context, studies have shown telemedicine to be equivalent to face-to-face care, and it can be an effective solution to increasing patient access to services, especially to specialist doctors.

Providing evidence of the efficacy and safety of remote treatment for different conditions in Brazil will contribute to improving patients' access to the public health system, including specialist doctors. This evidence can also help to remove restrictions placed on remote consultation by the Brazilian Federal Medicine Council, which currently restricts direct specialist-to-patient consultation. This model of improved access can help to meet the health needs of the population, breaking the geographical barriers that a country like Brazil imposes on the provision of health services. In addition to greater access to health care, the use of telemedicine has potential economic benefits for health systems and can be used safely to deliver a quality service.

Our expectations are that providing remote access to health care will result in improvements in the health and quality of life of patients with type 2 diabetes and reduce costs and that both patients and clinicians will benefit from and be satisfied with this technology.

\section{Acknowledgments}

The authors would like to thank Anna Maria Buehler and Jefferson Gomes Fernandes, MD for their invaluable contribution to the initial elaboration of this research protocol and Tiago da Veiga Pereira, who participated in the writing and technical editing of this manuscript. The study received funding from the SUS Institutional Development Support Program (PROADI-SUS) of the Ministry of Health of Brazil. 


\section{Conflicts of Interest}

None declared.

\section{References}

1. GBD 2016 Healthcare Access and Quality Collaborators. Measuring performance on the Healthcare Access and Quality Index for 195 countries and territories and selected subnational locations: a systematic analysis from the Global Burden of Disease Study 2016. The Lancet 2018 Jun;391(10136):2236-2271. [doi: 10.1016/S0140-6736(18)30994-2]

2. Feigin VL, Norrving B, George MG, Foltz JL, Roth GA, Mensah GA. Prevention of stroke: a strategic global imperative. Nat Rev Neurol 2016 Sep 22;12(9):501-512. [doi: 10.1038/nrneurol.2016.107] [Medline: 27448185]

3. Santos J, Vieira L, Pionorio M, Silva I. Diabetes mellitus in Brazil: risk factors, classification and complications. Int J Med Rev Case Rep 2019:1. [doi: 10.5455/ijmrcr.diabetes-mellitus-in-brazil]

4. Barreto ML. Health inequalities: a global perspective. Cien Saude Colet 2017 Jul;22(7):2097-2108 [FREE Full text] [doi: 10.1590/1413-81232017227.02742017] [Medline: 28723991]

5. Scheffer M, FMUSP, CFM. Cremesp. Demografia Médica no Brasil. 2018. URL: http://www.flip3d.com.br/web/pub/cfm/ index 10/?numero=15\&edicao=4278 [accessed 2020-12-05]

6. Norman AH. A formação em medicina de família no Brasil: a necessidade de caminhos convergentes. Rev Bras Med Fam Comunidade 2014 Jan 19;9(30):1-2. [doi: 10.5712/rbmfc9(30)875]

7. Almeida PFD, Giovanella L, Nunan BA. Coordenação dos cuidados em saúde pela atenção primária à saúde e suas implicações para a satisfação dos usuários. Saúde debate 2012 Sep;36(94):375-391. [doi: 10.1590/s0103-11042012000300010]

8. Maeyama MA, Calvo MCM. A Integração do Telessaúde nas Centrais de Regulação: a Teleconsultoria como Mediadora entre a Atenção Básica e a Atenção Especializada. Rev Bras Educ Med 2018 Jun;42(2):63-72. [doi: 10.1590/1981-52712015v42n2rb20170125]

9. Toledo FG, Triola A, Ruppert K, Siminerio LM. Telemedicine consultations: an alternative model to increase access to diabetes specialist care in underserved rural communities. JMIR Res Protoc 2012 Nov 07;1(2):e14 [FREE Full text] [doi: 10.2196/resprot.2235] [Medline: 23612044]

10. Timpel P, Oswald S, Schwarz PEH, Harst L. Mapping the Evidence on the Effectiveness of Telemedicine Interventions in Diabetes, Dyslipidemia, and Hypertension: An Umbrella Review of Systematic Reviews and Meta-Analyses. J Med Internet Res 2020 Mar 18;22(3):e16791 [FREE Full text] [doi: 10.2196/16791] [Medline: 32186516]

11. Elbert NJ, van Os-Medendorp H, van Renselaar W, Ekeland AG, Hakkaart-van Roijen L, Raat H, et al. Effectiveness and cost-effectiveness of ehealth interventions in somatic diseases: a systematic review of systematic reviews and meta-analyses. J Med Internet Res 2014 Apr 16;16(4):e110 [FREE Full text] [doi: 10.2196/jmir.2790] [Medline: 24739471]

12. Conselho Federal de Medicina. Resolução CFM no 1.643/2002. 2002. URL: https://sistemas.cfm.org.br/normas/visualizar/ resolucoes/BR/2002/1643 [accessed 2020-12-05]

13. Fatehi F, Martin-Khan M, Gray LC, Russell AW. Design of a randomized, non-inferiority trial to evaluate the reliability of videoconferencing for remote consultation of diabetes. BMC Med Inform Decis Mak 2014 Feb 14;14(1):11 [FREE Full text] [doi: 10.1186/1472-6947-14-11] [Medline: 24528569]

14. Ministério da Saúde. Insulinas análogas de ação rápida para o tratamento de diabetes mellitus tipo I: Relatório de recomendação. Comissão Nacional de Incorporação de Tecnologias no SUS (CONITEC). 2017. URL: http://conitec.gov.br/ images/Relatorios/2017/Relatorio Insulinas DiabetesTipo1 final.pdf [accessed 2020-12-09]

15. Costa AM, Franco EM, Marques LAA, Franco TB. Cartilha de Vigilancia Sanitaria. Agência Nacional de Vigilância Sanitária. 2004. URL: http://bvsms.saude.gov.br/bvs/publicacoes/cartilha vigilancia.pdf [accessed 2020-12-09]

16. Tambascia MA. Visão geral dos antidiabéticos orais tradicionais: Secretagogos, Inibidores da Alfa-glicosidase e Sensibilizadores de Insulina. Sociedade Brasileria de Diabetes: E-book 2 Diabetes pratica clinica. URL: $\underline{\text { https://ebook. }}$ diabetes.org.br/component/k2/item/

$\underline{\text { 87-capitulo-01-visao-geral-dos-antidiabeticos-orais-tradicionais-secretagogos-inibidores-da-alfa-glicosidase-e-sensibilizadores-de-insulina }}$ [accessed 2020-12-09]

17. Oliveira J, Vencio S. 2014-2015/Sociedade Brasileira de Diabetes. Diretrizes da Sociedade Brasileira de Diabetes. 2015. URL: https://www.diabetes.org.br/publico/images/2015/area-restrita/diretrizes-sbd-2015.pdf [accessed 2020-12-09]

18. Levey AS, Stevens LA. Estimating GFR using the CKD Epidemiology Collaboration (CKD-EPI) creatinine equation: more accurate GFR estimates, lower CKD prevalence estimates, and better risk predictions. Am J Kidney Dis 2010 Apr;55(4):622-627 [FREE Full text] [doi: 10.1053/j.ajkd.2010.02.337] [Medline: 20338463]

19. Maeyama MA, Dolny LL, Knoll RK. Atenção básica à saúde: aproximando teoria e prática. UNIVALI. 2018. URL: https:/ /www.univali.br/vida-no-campus/editora-univali/e-books/Documents/ecs/

Aten\%C3\%A7\%C3\%A30\%20B\%C3\%A1sica\%20\%C3\%A0\%20Sa\%C3\%BAde\%20Aproximando\%20Teoria\%20e\%20Pr\%C3\%A1tica. pdf [accessed 2020-12-09]

20. Maeyama MA, Calvo MCM. A Integração do Telessaúde nas Centrais de Regulação: a Teleconsultoria como Mediadora entre a Atenção Básica e a Atenção Especializada. Rev Bras Educ Med 2018 Jun;42(2):63-72. [doi: $\underline{10.1590 / 1981-52712015 v 42 n 2 r b 20170125]}$ 
21. Kaplan RS, Anderson SR. Time-driven activity-based costing. Harvard Business Review. 2004 Nov. URL: https://hbr.org/ 2004/11/time-driven-activity-based-costing [accessed 2020-12-09]

22. Kaplan RS, Anderson SR. Time-driven activity-based costing: a simpler and more powerful path to higher profits. Boston, MA: Harvard Business School Press; 2007.

23. Ahlqvist E, Storm P, Käräjämäki A, Martinell M, Dorkhan M, Carlsson A, et al. Novel subgroups of adult-onset diabetes and their association with outcomes: a data-driven cluster analysis of six variables. The Lancet Diabetes \& Endocrinology 2018 May;6(5):361-369. [doi: 10.1016/s2213-8587(18)30051-2]

24. International Diabetes Federation. 2020. URL: https://www.idf.org/e-library/epidemiology-research/diabetes-atlas.html [accessed 2020-12-09]

25. Fatehi F. Thesis: Videoconferencing for Clinical Management of Diabetes. University of Queensland. 2014. URL: http:/ lespace.library.uq.edu.au/view/UQ:347629 [accessed 2020-12-09]

26. Kalra S, Khandelwal D. The Hypoglycaemia Awareness Questionnare (HAQ). Journal of the Pakistan Medical Association 2018;68(2):3.

27. Yip MP, Chang AM, Chan J, MacKenzie AE. Development of the Telemedicine Satisfaction Questionnaire to evaluate patient satisfaction with telemedicine: a preliminary study. J Telemed Telecare 2003 Jun 24;9(1):46-50. [doi: 10.1258/135763303321159693] [Medline: 12641893]

28. Correr CJ, Pontarolo R, Melchiors AC, Rossignoli P, Fernández-Llimós F, Radominski RB. [Translation to portuguese and validation of the Diabetes Quality Of Life Measure (DQOL-Brazil)]. Arq Bras Endocrinol Metabol 2008 Apr;52(3):515-522. [doi: 10.1590/s0004-27302008000300012] [Medline: 18506277]

29. Bagattini M, Camey SA, Miguel SR, Andrade MV, de Souza Noronha KVM, de C Teixeira MA, et al. Electronic Version of the EQ-5D Quality-of-Life Questionnaire: Adaptation to a Brazilian Population Sample. Value Health Reg Issues 2018 Dec;17:88-93. [doi: 10.1016/j.vhri.2017.11.002] [Medline: 29754016]

30. Chow SC, Shao J, Wang H, Lokhnygina Y. Sample Size Calculations in Clinical Research, 3rd Edition. Boca Raton, FL: Chapman and Hall/CRC; Jan 01, 2018.

31. CONSORT 2010 checklist of information to include when reporting a randomized trial. CONSORT. 2010. URL: http:/ /www.consort-statement.org/media/default/downloads/CONSORT\%202010\%20Checklist.pdf [accessed 2020-12-09]

32. Piaggio G, Elbourne DR, Altman DG, Pocock SJ, Evans SJW, CONSORT Group. Reporting of noninferiority and equivalence randomized trials: an extension of the CONSORT statement. JAMA 2006 Mar 08;295(10):1152-1160. [doi:

10.1001/jama.295.10.1152] [Medline: 16522836]

33. Tunes da Silva G, Logan BR, Klein JP. Methods for equivalence and noninferiority testing. Biol Blood Marrow Transplant 2009 Jan;15(1 Suppl):120-127 [FREE Full text] [doi: 10.1016/j.bbmt.2008.10.004] [Medline: 19147090]

34. Walker E, Nowacki AS. Understanding equivalence and noninferiority testing. J Gen Intern Med 2011 Feb 21;26(2):192-196 [FREE Full text] [doi: 10.1007/s11606-010-1513-8] [Medline: 20857339]

35. Little RJ, D'Agostino R, Cohen ML, Dickersin K, Emerson SS, Farrar JT, et al. The Prevention and Treatment of Missing Data in Clinical Trials. N Engl J Med 2012 Oct 04;367(14):1355-1360. [doi: 10.1056/nejmsr1203730]

36. Jakobsen JC, Gluud C, Wetterslev J, Winkel P. When and how should multiple imputation be used for handling missing data in randomised clinical trials - a practical guide with flowcharts. BMC Med Res Methodol 2017 Dec 06;17(1):162 [FREE Full text] [doi: 10.1186/s12874-017-0442-1] [Medline: 29207961]

\author{
Abbreviations \\ ANCOVA: analysis of covariance \\ $\mathbf{H b A}_{1 \mathbf{c}}$ : glycated hemoglobin \\ ITT: intention-to-treat \\ SUS: Unified Health System (in Portuguese) \\ TDABC: time-driven activity-based costing
}

Edited by $G$ Eysenbach; submitted 19.08.20; peer-reviewed by E Franco, A Benis; comments to author 23.09.20; revised version
received 15.10.20; accepted 20.10.20; published 21.01 .21
Please cite as:
Rodrigues DLG, Belber GS, Padilha FVDQ, Spinel LF, Moreira FR, Maeyama MA, Pinho APNM, Júnior ÁA
Impact of Teleconsultation on Patients With Type 2 Diabetes in the Brazilian Public Health System: Protocol for a Randomized
Controlled Trial (TELEconsulta Diabetes Trial)
JMIR Res Protoc $2021 ; 10(1):$ :e23679
URL: $\underline{\text { https://www.researchprotocols.org/2021/1/e23679 }}$
doi: $\underline{10.2196 / 23679}$
PMID: $\underline{33475516}$


CDaniela Laranja Gomes Rodrigues, Gisele Silvestre Belber, Frederica Valle De Queiroz Padilha, Ligia Fonseca Spinel, Frederico Rafael Moreira, Marcos Aurélio Maeyama, Ana Paula Neves Marques Pinho, Álvaro Avezum Júnior. Originally published in JMIR Research Protocols (http://www.researchprotocols.org), 21.01.2021. This is an open-access article distributed under the terms of the Creative Commons Attribution License (https://creativecommons.org/licenses/by/4.0/), which permits unrestricted use, distribution, and reproduction in any medium, provided the original work, first published in JMIR Research Protocols, is properly cited. The complete bibliographic information, a link to the original publication on http://www.researchprotocols.org, as well as this copyright and license information must be included. 